\title{
Pengaruh Budaya Organisasi Dan Disiplin Terhadap Kinerja Karyawan Pada PT. Mega Perintis Tbk
}

\author{
${ }^{1}$ Lili Sularmi, Nurul Hikmah Apriyanti \\ Dosen Fakultas Ekonomi Universitas Pamulang \\ ${ }^{1}$ Email : lilisularmi.ls81@gmail.com
}

\begin{abstract}
ABSTRAK
Tujuan pada penelitian ini adalah untuk mengetahui pengaruh budaya organisasi terhadap kinerja karyawan, untuk mengetahui pengaruh disiplin kerja terhadap kinerja karyawan, dan untuk mengetahui pegaruh budaya organisasi dan disiplin kerja secara bersama-sama terhadap kinerja karyawan pada PT. Mega Perintis Tbk.

Metode yang digunakan adalah metode deskriptif dengan pendekatan asosiatif. Teknik sampling yang digunakan adalah proporsional random sampling menggunakan dengan sampel sebanyak 64 responden. Analisis data menggunakan analisis regresi, analisis koefisien korelasi, analisis koefisien determinasi dan uji hipotesis

Hasil penelitian ini adalah budaya organisasi berpengaruh positif dan signifikan terhadap kinerja karyawan sebesar $41,4 \%$. Uji hipotesis secara parsial diperoleh $\mathrm{t}$ hitung $>\mathrm{t}$ tabel atau $(6,623>1,999)$, sehingga $\mathrm{H}_{0}$ ditolak dan $\mathrm{H}_{1}$ diterima artinya terdapat pengaruh positif dan signifikan antara budaya organisasi terhadap kineja karyawan pada PT. Mega Perintis Tbk. Disiplin kerja berpengaruh positif dan signifikan terhadap kinerja karyawan sebesar 32,7\%. Uji hipotesis secara parsial diperoleh $\mathrm{t}$ hitung $>\mathrm{t}$ tabel atau $(5,483>1,999)$ sehingga $\mathrm{H}_{0}$ ditolak dan $\mathrm{H}_{2}$ diterima artinya terdapat pengaruh positif dan signifikan antara disiplin kerja terhadap kinerja karyawan pada PT. Mega Perintis Tbk. Uji hipotesis simultan budaya organisasi dan disiplin kerja berpengaruh positif dan signifikan terhadap kineja karyawan dengan koefisien determinasi sebesar 47,3\%, sedangkan sisanya sebesar 52,7\% dipengaruhi faktor lain. Uji hipotesis diperoleh nilai $F$ hitung $>F$ tabel atau $(33,915>2,760)$, dengan demikian Ho ditolak dan $\mathrm{H}_{3}$ diterima. Artinya terdapat pengaruh positif dan signifikan secara simultan antara budaya organisasi dan disiplin kerja terhadap kinerja karyawan pada PT. Mega Perintis Tbk.
\end{abstract}

\section{Kata Kunci : Budaya Organisasi, Disiplin Kerja dan Kinerja Karyawan.}




\section{PENDAHULUAN}

\section{A. Latar Belakang Masalah}

Keselarasan antar personal didalam organisasi merupakan kondisi yang dapat menentukan berhasil atau tidaknya suatu organisasi mencapai tujuannya. Variabel pada tingkatan organisasi dalam mencapai tujuannya adalah budaya organisasi. Budaya sebuah organisasi yang punya kemungkinan paling besar untuk membentuk standar dan etika tinggi adalah budaya yang tinggi toleransinya terhadap risiko tinggi, rendah, sampai dengan hal keagresifan, dan fokus pada sarana selain juga hasil.
PT. Mega Perintis Tbk adalah salah satu perusahaan fashion di Indonesia yang berfokus pada Man's Fashion. Perusahaan tersebut perkembangannya cukup pesat di era globalisasi saat ini. PT. Mega Perintis Tbk berpendapat bahwa manusia adalah asset dan faktor utama penentu kesuksesan perusahaan. Oleh karena itu PT. Mega Perintis Tbk selalu membina hubungan kerja jangka panjang yang saling membangun, sehingga tumbuh ikatan dan rasa kebersamaan antara karyawan dan perusahaan untuk mewujudkan peningkatan kesejahteraan yang berkelanjutan.

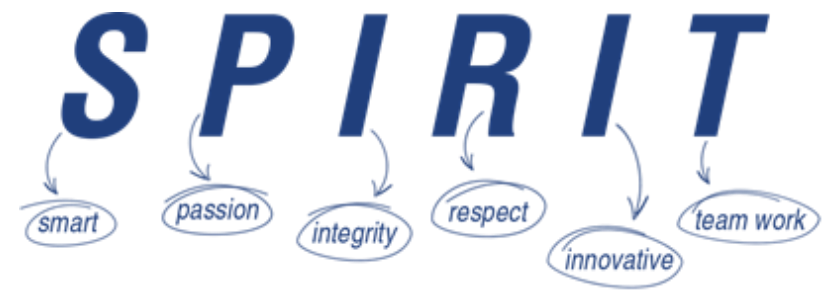

Gambar 1.1 Nilai Perusahaan PT. Mega Perintis Tbk

Budaya organisasi berkaitan erat dengan peningkatan kinerja karyawan dalam suatu organisasi. Semakin baik budaya organisasi, semakin besar dorongan para karyawan untuk maju bersama dengan organisasi lainnya. Budaya organisasi memiliki filosofi sendiri, perilaku dan pola pemikiran, prakter bisnis, kepribadian sendiri. Budaya organisasi dapat mempengaruhi perilaku, sikap dan efektifitas karyawan dalam organisasi tersebut.

Kedisiplinan dalam suatu organisasi merupakan tolak ukur hidupnya norma, tata tertib dan peraturan organisasi yang berhubungan dengan orang-orang terhadap tugas yang diberikan. Disiplin yang baik merupakan tanggung jawab karyawan terhadap tugas yang diberikan. Disiplin lebih banyak berasal dari diri karyawan itu sendiri. Salah satu bentuk disiplin adalah karyawan dapat menyelesaikan pekerjaan tepat waktu, masih banyaknya karyawan yang terlambat karena kurangnya disiplin pada diri karyawan. Pada tahun 2016 jumlah terlambat, sakit, izin dan abstain mendapat 91 orang atau 36,4\% dari jumlah hari kerja (JHK). Tahun 2017 turun 
menjadi 32\% namun tahun 2018 mengalami kenaikan menjadi $32,8 \%$. Keberhasilan suatu organisasi ditentukan oleh bertanggung jawabnya karyawan dalam melaksankan tugasnya dan tepat waktu pada saat masuk jam kantor, sedangkan dalam observasi yang telah dilakukan masih banyak karyawan yang menunda pelaksanaan tugas kantor, terlambat saat masuk jam kerja, keluar kantor pada saat jam-jam kerja dan kurangnya komunikasi antar karyawan dengan pimpinan mempengaruhi kinerja karyawan pada masing-masing individu, karena kinerja karyawan sendiri dipengaruhi oleh karakteristik individu dan faktor lingkungan perusahaan, baik suasana kerja lingkungan fisik maupun leadership dari pimpinan. Sedangkan para atasan sebagai motivator bagi para karyawan berusaha agar kinerja karyawan terus meningkat, perusahaan juga memberikan reward (bonus) yang sesuai dengan kinerja karyawan yang diberikan karyawan pada perusahaan.

Salah satu masalah yang dihadapi Indonesia saat ini adalah rendahnya sumber daya manusia. Apabila jumlah sumber daya manusia di Indonesia yang besar dapat didayagunakan secara profesional akan bermanfaat untuk menunjang pertumbuhan ekonomi di Indonesia. Agar dalam masyarakat tersedia sumber daya manusia yang berpendidikan, memberikan lapangan pekerjaan dan menyediakan berbagai fasilitas sosial yang memadai, penilaian kinerja PT. Mega Perintis Tbk tahun 2018 diatas hampir semua bagian belum mencapai target dalam pekerjaannya. Nilai tertinggi didapatkan oleh bagian ASS atau 3.10 dan yang mendapatkan nilai terendah yaitu Brand MCT atau 2.54. Dalam hal ini dapat diindikasi bahwa kinerja karyawan pada PT. Mega Perintis Tbk belum optimal.

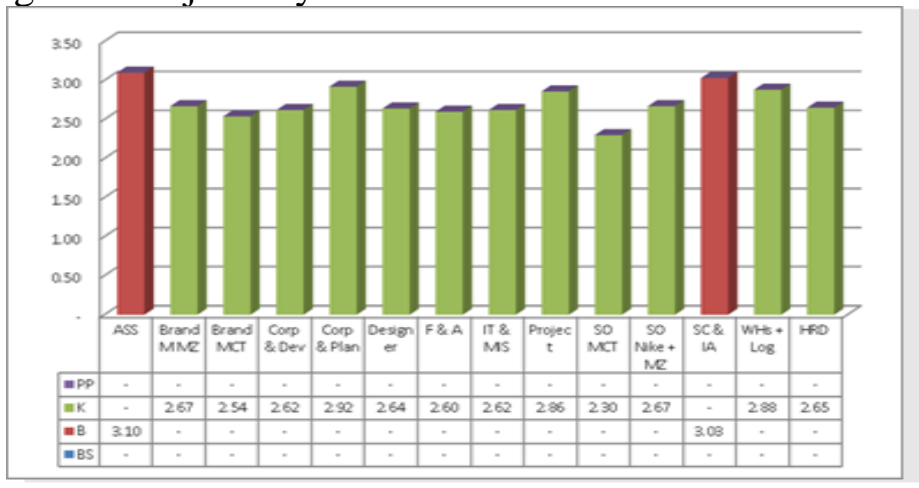

Gambar 1.2

Penilaian Kinerja PT. Mega Perintis Tbk

Berdasarkan kenyataan yang telah diamati melalui disiplin karyawan masih ada yang belum melaksanakan dengan baik. Perilaku yang sering muncul masih kurangnya kedisiplinan atau melanggar peraturan, meninggalkan pekerjaan tanpa izin, kehadiran karyawan yang kurang tepat waktu dan perilaku 
yang menunjukan semangat kerja menjadi turun. Dalam organisasi, karyawan melaksanakan tugasnya harus sesuai aturan dan pedoman yang telah ditetapkan oleh organisasi.

\section{B. Identifikasi Masalah}

Beberapa masalah-masalah yang di identifikasi adalah :

1. Kurangnya pemahaman karyawan terhadap budaya perusahaan.

2. Kurangnya kerjasama antara karyawan dengan departemen yang ada di PT. Mega Perintis Tbk.

3. Kurangnya komunikasi antara karyawan dengan pimpinan.

4. Kurangnya tanggung jawab karyawan dalam menyelesaikan pekerjaan.

5. Kurangnya tingkat kedisiplinan karyawan.
6. Kurangnya keteladanan kepemimpinan.

7. Kurangnya kesejahteraan karyawaan pada perusahaan.

8. Kurang optimalnya kinerja karyawan.

\section{Rumusan Masalah}

Permasalahan

pada

penelitian ini dirumuskan sebagai berikut:

1. Bagaimana pengaruh budaya organisasi terhadap kinerja karyawan pada PT. Mega Perintis Tbk?

2. Bagaimana pengaruh disiplin kerja terhadap kinerja karyawan pada PT. Mega Perintis Tbk?

3. Bagaimana pengaruh budaya organisasi dan disiplin kerja secara Bersama sama terhadap kinerja karyawan pada PT. Mega Perintis Tbk?

\section{Kerangka Berpikir}

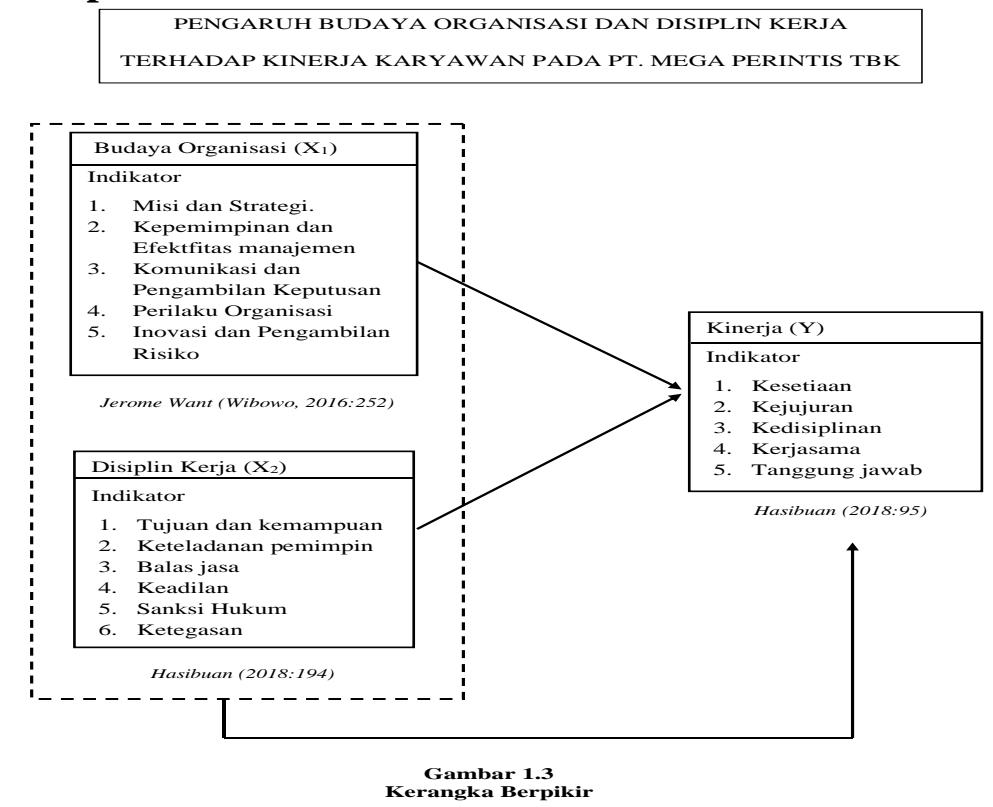

\section{E. Hipotesis}

Hipotesis yang jawaban sementara permasalahan yang diajukan terhadap diajukan dalam penelitian ini adalah sebagai berikut:

$\mathrm{Ho}_{1}$ : Diduga tidak terdapat pengaruh signifikan 
antara budaya organisasi terhadap kinerja karyawan pada PT. Mega Perintis Tbk secara parsial.

$\mathrm{Ha}_{1}$ : Diduga terdapat pengaruh yang signifikan antara budaya organisasi terhadap kinerja karyawan pada PT. Mega Perintis Tbk secara parsial.

$\mathrm{Ho}_{2}$ : Diduga tidak terdapat pengaruh yang signifikan antara disiplin kerja terhadap kinerja karyawan pada PT. Mega Perintis Tbk secara parsial.

$\mathrm{Ha}_{2}$ : Diduga terdapat pengaruh yang signifikan antara disiplin kerja terhadap kinerja karyawan pada PT. Mega Perintis Tbk secara parsial.

$\mathrm{Ho}_{3}$ : Diduga tidak terdapat pengaruh yang signifikan antara budaya organisasi dan disiplin kerja terhadap kinerja karyawan pada PT. Mega Perintis Tbk secara simultan.

$\mathrm{Ha}_{3}$ : Diduga terdapat pengaruh yang signifikan antara budaya organisasi dan disiplin kerja terhadap kinerja karyawan pada PT. Mega Perintis Tbk secara simultan.

\section{TINJAUAN PUSTAKA}

\section{A. Budaya Organisasi}

Menurut Robbins dalam Wibowo (2016:15), budaya organisasi adalah sebuah persepsi umum yang dipegang oleh anggota organisasi, suatu sistem tentang keberanian bersama. Menurut Mia Lasmi (2016:196), budaya organisasi adalah cara orang berprilaku dalam organisasi dan ini merupakan satu set norma yang terdiri dari keyakinan, sikap, nilainilai inti, dan pola perilaku bersama dalam organisasi.

Menurut Michael Zwell

dalam Wibowo (2016:15) menyatakan budaya korporasi sebagai cara hidup suatu organisasi yang diberikan melalui generasi penerus pekerja. Menurut Mangkunegara (2013:113), Budaya organisasi adalah seperangkat asumsi atau sistem keyakinan, nilai - nilai dan norma yang dikembangkan dalam organisasi yang dijadikan pedoman tingkah laku bagi anggota - anggotanya untuk mengatasi masalah adaptasi eksternal dan integrase internal.

Menurut Graham dalam Siswandi (2012:71) budaya organisasi adalah norma, keyakinan, sikap dan filosofi organisasi. Kebudayaan adalah suatu sistem nila, keyakinan dan norma-norma yang unik yang dimiliki secara bersama oleh anggota suatu organisasi. Kebudayaan juga menjadi suatu penyebab penting bagi keefektifan organisasi itu sendiri.

\section{B. Disiplin}

Di dalam kehidupan seharihari, dimana pun manusia berada, dibutuhkan peraturan-peraturan dan ketentuan-ketentuan yang akan mengatur dan membatasi setiap kegiatan dan prilakunya. Demikian juga kehidupan dalam 
suatu perusahaan akan sangat membutuhkan ketaatan dari anggota-anggotanya pada peraturan dan ketentuaan yang berlaku pada oraganisasi tersebut. Dengan kata lain kedisiplinan dalam bekerja sangat dibutuhkan, karena apa yang menjadi tujuan organisasi akan sukar dicapai bila tidak ada kedisiplinan dalam bekerja.

Menurut

Hasibuan (2018:193), Kedisiplinan adalah kesadaran dan kesediaan seseorang menaatin peraturan perusahaan dan norma-norma sosial yang berlaku. Kesadaran adalah sikap seseorang yang secara sukarela menaati semua peraturan dan sadar akan tugas dan tanggung jawabnya. Jadi, dia akan mematuhi atau mengerjakan semua tugasnya dengan baik, bukan atas paksaan. Kesediaan adalah suatu sikap, dan perbuatan seseorang yang sesuai dengan peraturan perusahaan, baik yang tertulis maupun tidak.

Menurut Keith Davis (Mangkunegara, 2017:129) mengemukakan bahwa "Dicipline is management action to enforce organization standards". Berdasarkan pendapat Keiht Davis, disiplin kerja dapat diartikan sebagai pelaksanaan manajemen untuk memperteguh pedoman-pedoman organisasi.

Menurut Singodimedjo (Sutrisno, 2017:86), mengatakan disiplin adalah sikap kesediaan dan kerelaan seseorang untuk mematuhi dan menaati normanorma peraturan yang berlaku disekitarnya. Menurut Veitzhal Rivai (2014:183) mendefinisikan disiplin kerja adalah suatu alat dipergunakan para manager untuk berkomunikasi dengan karyawan agar mereka bersedia untuk mengubah suatu perilaku serta sebagai suatu upaya untuk meningkatkan kesadaran dan kesedian seorang dalam memenuhi segala peraturan perusahaan.

Menurut Setyaningdyah (2013:145) disiplin kerja adalah kebijakan bergeser individu untuk menjadi diri bertanggung jawab untuk mematuhi peraturan lingkungan (organisasi). Sedangkan menurut Siagian (2012:305) mengemukakan bahwa "Disiplin karyawan dalam manajemen sumber daya manusia berangkat dari pandangan bahwa tidak ada manusia yang sempurna, lepas dari kesalahan dan kekhilafan".

Dari beberapa pendapat diatas dsiplin kerja merupakan suatu bentuk upaya pegawai yang berusaha memperbaiki dan membentuk pengetahuan, sikap dan perilaku karyawan sehingga perilaku karyawan tersebut secara sukarela berusaha bekerja secara koperatif dengan para karyawan lain serta meningkatkan prestasi kerja.

\section{Kinerja}

Menurut Mangkunegara (2017:67) Kinerja (prestasi kerja) adalah hasil kerja secara kualitas dan kuantitas yang dicapai oleh seorang pegawai dalam melaksanakan tugasnya sesuai dengan tanggung jawab yang diberikan kepadanya. Menurut Hasibuan (2018:95) Kinerja karyawan adalah hasil kerja yang dicapai seseorang dalam melaksanakan tugas - tugas yang 
dibebankan kepadanya didasarkan atas kecakapan, pengalaman, kesungguhan, serta waktu.

Menurut Rivai (2014:15) Kinerja karyawan adalah kesediaan seseorang atau kelompok orang untuk melakukan sesuatu kegiatan dan menyempurnakannya sesuai dengan tanggung jawabnya dengan hasil seperti yang diharapkan.

Menurut Bernardin dalam Sudarmanto (2014:8) menyatakan bahwa kinerja merupakan catatan hasil yang diproduksi (dihasilkan) atas fungsi pekerjaan tertentu atau aktivitas-aktivitas selama periode waktu tertentu. Dari definisi tersebut, Bernardin menekankan pengertian kinerja sebagai hasil, bukan sekedar sifat (trait) dan perilaku.

\section{METODE PENELITIAN}

Penelitian ini dilaksanakan di PT. Mega Perintis Tbk yang beralamat di Jalan Karet Pedurenan No. 240, Karet Kuningan - Setiabudi, Jakarta Selatan. No. Tlp : 0215733888. Populasi yang digunakan dalam penelitian ini adalah 174 orang karyawan. Penentuan besarnya sampel menggunakan rumus Slovin (Sugiyono, 2016:82) sebagai berikut :

Rumus Slovin $n=\frac{N}{1+N(e)^{2}}$

Dengan jumlah populasi (N) sebesar 174 karyawan. Maka dapat diperoleh besarnya sampel sebagai berikut :

$$
\begin{aligned}
n & =\frac{N}{1+N(e)^{2}} \\
& =\frac{174}{\begin{array}{c}
1+174(0,1)^{2} \\
\text { Metode }
\end{array} \text { pengumpulan data }}=64 \text { orang karyawan, }
\end{aligned}
$$
menggunakan data primer yaitu observasi dan penyebaran kuesioner serta data sekunder yaitu dokumentasi dan studi kepustakaan, uji instrumen penelitian menggunakan uji validitas dan uji reliabilitas, uji asumsi klasik, dalam penelitian ini uji asumsi klasik yang digunakan adalah meliputi: uji normalitas, uji multikolinearitas, uji autokorelasi, dan uji heterokedastisitas.

Metode analisis data menggunakan analisis deskriptif, adapun tahapan analisis yang dilakukan adalah analisis regresi linier sederhana dan linier berganda, analisis koefisien korelasi (R), analisis koefisien determinasi $(R$ Square) danpengujian hipotesis

\section{HASIL PENELITIAN}

\section{Uji Validitas Instrumen}

Tabel 4.1

Hasil Uji Validitas

\begin{tabular}{|c|c|c|c|c|c|}
\hline $\begin{array}{c}\text { Item } \\
\text { Kuesioner }\end{array}$ & $\begin{array}{c}\text { Chronbatch Alpha } \\
\text { Budaya Organisasi }\end{array}$ & $\begin{array}{c}\text { Chronbatch Alpha } \\
\text { Disiplin }\end{array}$ & Chronbatch Alpha Kinerja & $\begin{array}{c}\text { Standar } \\
\text { Chronbatch Alpha }\end{array}$ & Keputusan \\
\hline 1. & 0.308 & 0.422 & 0.440 & 0.30 & Valid \\
\hline 2. & 0.302 & 0.505 & 0.414 & 0.30 & Valid \\
\hline 3. & 0.391 & 0.401 & 0.512 & 0.30 & Valid \\
\hline 4. & 0.537 & 0.462 & 0.401 & 0.30 & Valid \\
\hline 5. & 0.719 & 0.512 & 0.515 & 0.30 & Valid \\
\hline 6. & 0.369 & 0.347 & 0.377 & 0.30 & Valid \\
\hline 7. & 0.662 & 0.631 & 0.697 & 0.30 & Valid \\
\hline 8. & 0.693 & 0.441 & 0.655 & 0.30 & Valid \\
\hline
\end{tabular}




\begin{tabular}{|c|c|c|c|c|c|}
\hline $\begin{array}{c}\text { Item } \\
\text { Kuesioner }\end{array}$ & $\begin{array}{c}\text { Chronbatch Alpha } \\
\text { Budaya Organisasi }\end{array}$ & $\begin{array}{c}\text { Chronbatch Alpha } \\
\text { Disiplin }\end{array}$ & $\begin{array}{c}\text { Standar } \\
\text { Chronbatch Alpha Kinerja }\end{array}$ & Keputusan \\
\hline 9. & 0.721 & 0.624 & 0.660 & 0.30 & Valid \\
\hline 10. & 0.463 & 0.624 & 0.373 & 0.30 & Valid \\
\hline
\end{tabular}

Sumber: Data Primer diolah.

Berdasarkan data tabel di atasdiperoleh nilai Standar Chronbatch Alpha > Standar Chronbatch Alpha 0.30, dengan demikian maka semua item kuesioner dinyatakan valid. Untuk itu kuesioner yang digunakan layak untuk diolah sebagai data penelitian

\section{Uji Reliabilitas Instrumen}

Tabel 4.2

Hasil Uji Reliabilitas Variabel Independen dan Dependen

\begin{tabular}{|c|c|c|c|l|}
\hline No. & Variabel & $\begin{array}{c}\text { Coeficient } \\
\text { Alpha }\end{array}$ & $\begin{array}{c}\text { Standar } \\
\text { Chronbach } \\
\text { Alpha }\end{array}$ & Keputusan \\
\hline 1 & $\begin{array}{c}\text { Budaya Organisasi } \\
\text { (X1) }\end{array}$ & 0.692 & 0.60 & Reliabel \\
\hline 2 & Disiplin Kerja (X2) & 0.662 & 0.60 & Reliabel \\
\hline 3 & $\begin{array}{c}\text { Kinerja Karyawan } \\
\text { (Y) }\end{array}$ & 0.673 & 0.60 & Reliabel \\
\hline
\end{tabular}

Sumber: Data Primer diolah, 2019.

Berdasarkan hasil pengujian pada tabel 4.4 di atas, menunjukkan bahwa variabel budaya organisasi (X1), disiplin kerja (X2) dan kinerja karyawan (Y) dinyatakan reliabel, hal itu dibuktikan dengan masing-masing variabel memiliki nilai Coeficien Alpha > Chronbath Alpha 0,60.

3. Pengujian Asumsi Klasik (Uji Prasyarat Data)

a. Uji Normalitas

Tabel 4.3

Hasil Uji Normalitas Dengan

Kolmogorov-Smirnov Test

\begin{tabular}{|c|c|c|c|c|c|c|}
\hline \multicolumn{7}{|c|}{ Tests of Normality } \\
\hline & \multicolumn{3}{|c|}{$\begin{array}{l}\text { Kolmogorov- } \\
\text { Smirnov }^{\mathrm{a}}\end{array}$} & \multicolumn{3}{|c|}{ Shapiro-Wilk } \\
\hline & Statistic & $\mathrm{df}$ & Sig. & Statistic & Df & Sig. \\
\hline $\begin{array}{l}\text { Kinerja } \\
\text { Karyawan } \\
\text { (Y) }\end{array}$ & .092 & 64 & $.200^{*}$ & .967 & 64 & .080 \\
\hline *. This is a & wer bc & 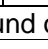 & the & sign & n & \\
\hline
\end{tabular}

Sumber: Data primer diolah, 2019.

Berdasarkan hasil pengujian pada tabel di atas, diperoleh nilai signifikansi $\alpha=$ 0,200 dimana nilai tersebut lebih besar dari nilai $\alpha=0,050$ atau $(0,200>0,050)$. Dengan demikian maka asumsi distribusi persamaan pada uji ini adalah normal.

b. Uji Multikolinearitas :

Tabel 4.4

Hasil Pengujian Multikolinearitas

Dengan Collinearity Statistic

Kinerja Karyawan Sebagai Variabel Dependen

\begin{tabular}{|c|c|c|c|c|c|c|c|}
\hline \multirow[b]{3}{*}{ Model } & \multicolumn{3}{|c|}{ Coefficients $^{\mathrm{a}}$} & \multirow{3}{*}{$t$} & \multirow{3}{*}{$\begin{array}{l}\text { Si } \\
\text { g. }\end{array}$} & \multirow{2}{*}{\multicolumn{2}{|c|}{$\begin{array}{c}\text { Colline } \\
\text { arity } \\
\text { Statistic } \\
\text { S }\end{array}$}} \\
\hline & \multicolumn{2}{|c|}{$\begin{array}{c}\text { Unstandar } \\
\text { dized } \\
\text { Coefficient } \\
\mathrm{s} \\
\end{array}$} & \multirow{2}{*}{\begin{tabular}{|c|}
$\begin{array}{c}\text { Standar } \\
\text { dized } \\
\text { Coefficie } \\
\text { nts }\end{array}$ \\
Beta \\
\end{tabular}} & & & & \\
\hline & B & $\begin{array}{c}\text { Std. } \\
\text { Error }\end{array}$ & & & & $\begin{array}{c}\text { To } \\
\text { I }\end{array}$ & VIF \\
\hline \begin{tabular}{l|l} 
(Const \\
ant)
\end{tabular} & $\begin{array}{l}8.4 \\
35 \\
\end{array}$ & $\begin{array}{c}3.76 \\
2 \\
\end{array}$ & & $\begin{array}{r}2.2 \\
42 \\
\end{array}$ & $\begin{array}{l}.0 \\
29\end{array}$ & & \\
\hline \begin{tabular}{|l} 
Buday \\
a \\
Organi \\
sasi \\
$(\mathrm{X} 1)$ \\
\end{tabular} & $\begin{array}{c}.46 \\
3\end{array}$ & . 091 & 491 & $\begin{array}{l}5.0 \\
76\end{array}$ & $\begin{array}{l}.0 \\
00\end{array}$ & $\begin{array}{l}.8 \\
28\end{array}$ & $\begin{array}{l}1.2 \\
07\end{array}$ \\
\hline $\begin{array}{l}\text { Disiplin } \\
\text { Kerja } \\
\text { (X2) }\end{array}$ & $\begin{array}{c}.35 \\
0\end{array}$ & .092 & .368 & $\begin{array}{c}3.8 \\
01\end{array}$ & $\begin{array}{l}.0 \\
00\end{array}$ & $\begin{array}{l}.8 \\
28\end{array}$ & $\begin{array}{l}1.2 \\
07\end{array}$ \\
\hline
\end{tabular}

a. Dependent Variable: Kinerja Karyawan (Y)

Sumber: Data primer diolah, 2019.

Berdasarkan

hasil pengujian multikolinieritas pada tabel di atas diperoleh nilai tolerance masing-masing variabel bebas yaitu budaya organisasi sebesar 0,828 dan disiplin kerja sebesar 0,828, dimana kedua nilai tersebut kurang dari 1, dan nilai Variance Inflation Factor (VIF) variabel budaya organisasi 
sebesar 1,207 serta disiplin kerja sebesar 1,207 dimana nilai tersebut kurang dari 10. Dengan demikian model regresi ini tidak ada multikolinearitas.

\section{c. Uji Autokorelasi}

Tabel 4.5

Uji Durbin-Watson

\begin{tabular}{|c|c|c|c|c|c|}
\hline \multicolumn{6}{|c|}{ Model Summary ${ }^{b}$} \\
\hline Model & $\mathrm{R}$ & $\begin{array}{c}R \\
\text { Square }\end{array}$ & $\begin{array}{l}\text { Adjusted } \\
\text { R Square }\end{array}$ & $\begin{array}{l}\text { Std. Error } \\
\text { of the } \\
\text { Estimate }\end{array}$ & $\begin{array}{l}\text { Durbin- } \\
\text { Watson }\end{array}$ \\
\hline 1 & $.726^{\mathrm{a}}$ & .527 & .511 & 2.476 & 1.833 \\
\hline
\end{tabular}

Sumber: Data Primer diolah, 2019.

Berdasarkan

hasil

pengujian pada tabel di atas, model regresi ini tidak ada autokorelasi, hal ini dibuktikan dengan nilai Durbin-Watson sebesar 1.833 yang berada diantara interval $1.550-2.460$.

\section{d. Uji Heteroskedastisitas}

Tabel 4.6

Hasil Pengujian

Heteroskesdastisitas Dengan $\boldsymbol{U} \boldsymbol{j i}$

Glejser

\begin{tabular}{|c|c|c|c|c|c|c|}
\hline \multicolumn{7}{|c|}{ Coefficients $^{a}$} \\
\hline \multirow{2}{*}{\multicolumn{2}{|c|}{ Model }} & \multicolumn{2}{|c|}{$\begin{array}{l}\text { Unstandardized } \\
\text { Coefficients }\end{array}$} & \multirow{2}{*}{$\begin{array}{c}\text { Standardized } \\
\text { Coefficients } \\
\text { Beta } \\
\end{array}$} & \multirow[b]{2}{*}{ t } & \multirow[b]{2}{*}{ Sig. } \\
\hline & & B & $\begin{array}{l}\text { Std. } \\
\text { Error }\end{array}$ & & & \\
\hline \multirow[t]{3}{*}{1} & (Constant) & .957 & 2.187 & & .438 & .663 \\
\hline & $\begin{array}{l}\text { Budaya } \\
\text { Organisasi } \\
\text { (X1) }\end{array}$ & -.082 & .053 & -.210 & 1.547 & .127 \\
\hline & $\begin{array}{l}\text { Disiplin } \\
\text { Kerja (X2) }\end{array}$ & .105 & .054 & .266 & 1.961 & .054 \\
\hline
\end{tabular}

Sumber: Data primer diolah, 2019.

Berdasarkan

hasil pengujian pada tabel di atas, glejser test model pada variabel budaya organisasi $\left(\mathrm{X}_{1}\right)$ diperoleh nilai probability signifikansi (Sig.) sebesar 0,127 dan disiplin kerja $\left(\mathrm{X}_{2}\right)$ diperoleh nilai probability signifikansi (Sig.) sebesar 0,054 dimana keduanya nilai signifikansi (Sig.) > 0,05. Dengan demikian regression model pada data ini tidak ada gangguan heteroskesdastisitas, sehingga model regresi ini layak dipakai sebagai data penelitian.

\section{A. Analisis Deskriptif dan Verifikatif}

\section{Analisis \\ Deskriptif}

Karakteristik Responden

a. Responden Berdasarkan Jenis Kelamin

Tabel 4.7

Karakteristik Responden

Berdasarkan Jenis Kelamin

\begin{tabular}{|c|l|c|c|c|c|}
\hline \multicolumn{5}{|c|}{ Jenis Kelamin } \\
\hline \multicolumn{2}{|c|}{} & Frequency & Percent & $\begin{array}{c}\text { Valid } \\
\text { Percent }\end{array}$ & $\begin{array}{c}\text { Cumulative } \\
\text { Percent }\end{array}$ \\
\hline \multirow{3}{*}{ Valid } & Laki-laki & 39 & 60.9 & 60.9 & 60.9 \\
\cline { 2 - 6 } & Perempuan & 25 & 39.1 & 39.1 & 100.0 \\
\cline { 2 - 6 } & Total & 64 & 100.0 & 100.0 & \\
\hline
\end{tabular}

Sumber: Data primer diolah.

Berdasarkan data di atas, responden yang berjenis kelamin laki-laki sebanyak 39 orang atau $60,9 \%$, sedangkan yang berjenis kelamin perempuan sebanyak 25 orang atau $39,1 \%$.

\section{b. Responden Berdasarkan} Usia

Tabel 4.8

Karakteristik Responden

Berdasarkan Usia

\begin{tabular}{|c|c|c|c|c|c|}
\hline \multicolumn{6}{|c|}{ Usia } \\
\hline & & Frequency & Percent & $\begin{array}{c}\text { Valid } \\
\text { Percent }\end{array}$ & $\begin{array}{c}\text { Cumulative } \\
\text { Percent }\end{array}$ \\
\hline \multirow[t]{5}{*}{ Valid } & $\begin{array}{l}20-25 \\
\text { Tahun }\end{array}$ & 11 & 17.2 & 17.2 & 17.2 \\
\hline & $\begin{array}{l}26-35 \\
\text { Tahun }\end{array}$ & 14 & 21.9 & 21.9 & 39.1 \\
\hline & $\begin{array}{l}36-45 \\
\text { Tahun }\end{array}$ & 35 & 54.7 & 54.7 & 93.8 \\
\hline & $\begin{array}{l}>45 \\
\text { Tahun }\end{array}$ & 4 & 6.3 & 6.3 & 100.0 \\
\hline & Total & 64 & 100.0 & 100.0 & \\
\hline
\end{tabular}

Data di atas, responden yang berusia antara 17-25 tahun sebanyak sebanyak 11 orang atau $17,2 \%$, yang 
berusia antara 26-35 tahun sebanyak 14 orang atau $21,9 \%$, yang berusia antara 36-45 tahun sebanyak 35 orang atau $54,7 \%$ dan yang berusia $>45$ tahun sebanyak 4 orang atau $6,3 \%$.

c. Karakteristik Responden Berdasarkan Pendidikan Tabel 4.9

Karakteristik Responden Berdasarkan Pendidikan

\begin{tabular}{|c|l|c|c|c|c|}
\hline \multicolumn{7}{|c|}{} & Pendidikan \\
\hline \multirow{2}{|c|}{} & Frequency & Percent & $\begin{array}{c}\text { Valid } \\
\text { Percent }\end{array}$ & $\begin{array}{c}\text { Cumulative } \\
\text { Percent }\end{array}$ \\
\hline \multirow{1}{*}{ Valid } & SLTA & 9 & 14.1 & 14.1 & 14.1 \\
\cline { 2 - 6 } & Diploma & 4 & 6.3 & 6.3 & 20.3 \\
\cline { 2 - 6 } & $\begin{array}{l}\text { Sarjana } \\
\text { (S1) }\end{array}$ & 39 & 60.9 & 60.9 & 81.3 \\
\cline { 2 - 6 } & $\begin{array}{l}\text { Pasca } \\
\text { Sarjana } \\
\text { (S2) }\end{array}$ & 12 & 18.8 & 18.8 & 100.0 \\
\cline { 2 - 6 } & Total & 64 & 100.0 & 100.0 & \\
\hline
\end{tabular}

Sumber: Data primer diolah, 2019

Berdasarkan data di atas, responden yang berpendidikan SLTA sebanyak 9 orang atau $14,1 \%$, yang berpendidikan Diploma sebanyak 4 orang atau 6,3\%, yang berpendidikan S1 sebanyak 39 orang atau $60,9 \%$, dan yang berpendidikan S2 sebanyak 12 orang atau $18,8 \%$.

\section{d. Penilaian}

\section{Responden}

Berdasar Pada Variabel Budaya Organisasi $\left(\mathrm{X}_{1}\right)$

Tanggapan responden atas pernyataan pada variabel budaya organisasi diperoleh rata-rata skor 3.76 termasuk pada rentang skala 3,40-4,19 dengan kriteria baik. Responden yang menjawab sangat setuju dan setuju sebesar $62,2 \%$ dan responden yang menjawab kurang setuju dan tidak setuju mencapai $37,8 \%$.
Tanggapan responden pada variabel disiplin kerja diperoleh rata-rata skor 3.86 termasuk pada rentang skala 3,40-4,19 dengan kriteria baik. Responden yang menjawab sangat setuju dan setuju sebesar $61,9 \%$ dan responden yang menjawab kurang setuju dan tidak setuju mencapai $38,1 \%$.

Tanggapan responden variabel kinerja karyawan diperoleh rata-rata skor sebesar 3.91 termasuk pada rentang skala 3,40-4,19 dengan kriteria baik. Responden yang menjawab sangat setuju dan setuju sebesar $71,4 \%$ dan responden yang menjawab kurang setuju dan tidak setuju mencapai $28,6 \%$.

2. Uji Statistik
a. Analisis
Regresi
Linier
Berganda.

Tabel 4.10

Hasil Pengolahan Regresi

Berganda Variabel Budaya

Organisasi $\left(\mathrm{X}_{1}\right)$ dan Disiplin

Kerja ( $\left.\mathbf{X}_{2}\right)$ Terhadap Kinerja

Karyawan (Y)

\begin{tabular}{|c|c|c|c|c|c|}
\hline \multirow[b]{3}{*}{ Model } & \multicolumn{3}{|c|}{ Coefficients $^{a}$} & \multirow[b]{3}{*}{$t$} & \multirow[b]{3}{*}{ Sig. } \\
\hline & \multicolumn{2}{|c|}{$\begin{array}{r}\text { Unstandardized } \\
\text { Coefficients }\end{array}$} & \multirow{2}{*}{$\begin{array}{c}\begin{array}{c}\text { Standardized } \\
\text { Coefficients }\end{array} \\
\text { Beta }\end{array}$} & & \\
\hline & B & $\begin{array}{l}\text { Std. } \\
\text { Error }\end{array}$ & & & \\
\hline 1 (Constant) & 8.435 & 3.762 & & 2.242 & .029 \\
\hline $\begin{array}{c}\text { Budaya } \\
\text { Organisasi } \\
\text { (X1) }\end{array}$ & .463 & .091 & .491 & 5.076 & .000 \\
\hline \begin{tabular}{|c|} 
Disiplin Kerja \\
$(\mathrm{X} 2)$
\end{tabular} & .350 & .092 & .368 & 3.801 & .000 \\
\hline
\end{tabular}

Sumber: Data primer diolah, 2019

Berdasarkan hasil analisis perhitungan regresi pada tabel di atas, maka dapat diperoleh persamaan regresi $\mathrm{Y}=8,435+$ $0,463 X_{1}+0,350 X_{2}$. 
b. Analisis Koefisien Korelasi (r)

Tabel 4.11

Hasil Analisis Koefisien Korelasi

Secara Simultan Antara Variabel

Budaya Organisasi $\left(\mathrm{X}_{1}\right)$ dan

Disiplin Kerja $\left(\mathbf{X}_{2}\right)$ Terhadap

Kinerja Karyawan (Y)

\begin{tabular}{|c|c|c|c|c|}
\hline \multicolumn{5}{|c|}{ Model Summary } \\
\hline Model & $\mathrm{R}$ & $\begin{array}{c}\mathrm{R} \\
\text { Square }\end{array}$ & $\begin{array}{c}\text { Adjusted } \\
\mathrm{R} \\
\text { Square }\end{array}$ & $\begin{array}{l}\text { Std. Error of } \\
\text { the Estimate }\end{array}$ \\
\hline 1 & $.726^{a}$ & .527 & .511 & 2.476 \\
\hline $\begin{array}{l}\text { a. Pre } \\
\text { Buday }\end{array}$ & $\begin{array}{l}\text { ctors: } \\
\text { Orgar }\end{array}$ & $\begin{array}{l}\text { Constan } \\
\text { isasi (X1 }\end{array}$ & , Disiplin & Kerja (X2), \\
\hline
\end{tabular}

Berdasarkan pada hasil pengujian pada tabel di atas, diperoleh nilai $R$ (koefisien korelasi) sebesar 0,726 artinya variabel budaya organisasi $\left(\mathrm{X}_{1}\right)$ dan disiplin kerja (X2) mempunyai tingkat pengaruh atau hubungan yang kuat terhadap kinerja karyawan (Y).

c. Analisis Koefisien Determinasi ( $R$ Square).

Tabel 4.12

Hasil Analisis Koefisien

Determinasi Secara Simultan

Antara Variabel Budaya

Organisasi $\left(\mathrm{X}_{1}\right)$ dan Disiplin Kerja

(X2)

\begin{tabular}{|l|c|r|r|c|}
\hline \multicolumn{4}{|c|}{ Model Summary } \\
\hline & & $\mathrm{R}$ & $\begin{array}{c}\text { Adjusted } \\
\mathrm{R}\end{array}$ & $\begin{array}{c}\text { Std. Error of the } \\
\text { Estimate }\end{array}$ \\
\hline 1 & $.726^{\mathrm{a}}$ & .527 & .511 & 2.476 \\
\hline
\end{tabular}

a. Predictors: (Constant), Disiplin Kerja (X2), Budaya Organisasi (X1)

Sumber: Data primer diolah, 2019

Berdasarkan pada hasil pengujian pada tabel di atas, diperoleh nilai $R$-square sebesar 0,527 maka dapat disimpulkan bahwa variabel budaya organisasi $\left(\mathrm{X}_{1}\right)$ dan disiplin kerja

(X2) berpengaruh terhadap variabel Kinerja karyawan (Y) sebesar $\quad 52,7 \%$ sedangkan sisanya sebesar $47,3 \%$ dipengaruhi oleh faktor lain yang tidak dilakukan penelitian.

d. Pengujian Hipotesis

Tabel 4.13

Hasil Hipotesis (Uji F)

Simultan

ANOVA $^{a}$

\begin{tabular}{|l|l|l|r|r|c|c|}
\hline \multicolumn{7}{|c|}{ ANOVA $^{\mathrm{a}}$} \\
\hline \multirow{2}{*}{ Model } & $\begin{array}{c}\text { Sum of } \\
\text { Squares }\end{array}$ & $\begin{array}{c}\text { Mean } \\
\text { Square }\end{array}$ & $\mathrm{F}$ & Sig. \\
\hline \multirow{2}{*}{1} & Regression & 415.801 & 2 & 207.901 & 33.915 & $.000^{\mathrm{b}}$ \\
\cline { 2 - 7 } & Residual & 373.933 & 61 & 6.130 & & \\
\cline { 2 - 7 } & Total & 789.734 & 63 & & & \\
\hline
\end{tabular}

a. Dependent Variable: Kinerja Karyawan $(\mathrm{Y})$

b. Predictors: (Constant), Disiplin Kerja (X2), Budaya Organisasi (X1)

Sumber: Data Primer diolah, 2019

Berdasarkan pada hasil pengujian pada tabel di atas diperoleh nilai $F_{\text {hitung }}>F_{\text {tabel }}$ atau $(33,915>2,760)$, hal ini juga diperkuat dengan $\rho$ value < Sig.0,05 atau $(0,000$ $<0,05)$. Dengan demikian maka $\mathrm{H}_{0}$ ditolak dan $\mathrm{H}_{3}$ diterima, hal ini menunjukkan bahwa terdapat pengaruh positif dan signifikan secara simultan antara budaya organisasi dan disiplin kerja terhadap Kinerja karyawan pada PT. Mega Perintis Tbk.

\section{KESIMPULAN DAN SARAN}

\section{A. Kesimpulan}

1. Budaya organisasi (X1) berpengaruh positif dan signifikan terhadap kinerja karyawan (Y) dengan nila koefisien korelasi sebesar 0,644 artinya kedua variabel memiliki pengaruh yang kuat dengan koefisien determinasi sebesar 41,4\%. Uji hipotesis 
diperoleh $\mathrm{t}$ hitung $>\mathrm{t}$ tabel atau $(6,623>1,999)$, hal ini diperkuat dengan probability signifikansi $0,000<0,05$, dengan demikian $\mathrm{H} 0$ ditolak dan $\mathrm{H} 1$ diterima artinya terdapat pengaruh positif dan signifikan antara budaya organisasi terhadap kinerja karyawan pada PT. Mega Perintis Tbk.

2. Disiplin kerja (X2) berpengaruh positif dan signifikan terhadap kinerja karyawan (Y) dengan nilai koefisien korelasi sebesar 0,571 artinya kedua memiliki pengaruh yang sedang dengan koefisien determinasi sebesar 32,7\%. Uji hipotesis diperoleh $\mathrm{t}$ hitung $>\mathrm{t}$ tabel atau $(5,483>1,999)$, hal ini diperkuat dengan probability signifikansi $0,000<0,05$, dengan demikian $\mathrm{H} 0$ ditolak dan $\mathrm{H} 2$ diterima artinya terdapat pengaruh positif dan signifikan antara disiplin kerja (X2) terhadap kinerja karyawan (Y) pada PT. Mega Perintis Tbk

3. Budaya organisasi (X1) dan disiplin kerja (X2) berpengaruh positif dan signifikan terhadap kinerja karyawan (Y) dengan persamaan regresi $\mathrm{Y}=8,435+$ $0,463 X 1+0,350 \times 2$ Nilai koefisien korelasi diperoleh sebesar 0,726 artinya variabel bebas dengan variabel terikat memiliki pengaruh yang kuat dengan koefisien determinasi atau pengaruh secara simultan sebesar $52,7 \%$ sedangkan sisanya sebesar $47,3 \%$ dipengaruhi faktor lain yang tidak diteliti dalam penelitian. Uji hipotesis diperoleh nilai $\mathrm{F}$ hitung $>\mathrm{F}$ tabel atau $(33,915>2,760)$, hal tersebut juga diperkuat dengan probability signifikansi $0,000<0,05$. Dengan demikian $\mathrm{H} 0$ ditolak dan $\mathrm{H} 3$ diterima. Artinya terdapat pengaruh positif dan signifikan secara simultan antara budaya organisasi dan disiplin kerja terhadap kinerja karyawan pada PT. Mega Perintis Tbk.

\section{B. Saran}

1. Variabel budaya organisasi (X1) pernyataan yang paling lemah adalah 10 yaitu "Saya berani menghadapi masalahmasalah yang timbul dalam pekerjaan" dimana hanya mencapai score sebesar 3,61. Untuk lebih baik lagi perusahaan harus menumbuhkan dan membangun rasa integrity atau kepercayaan pada karyawan agar setiap permasalahan yang dilakukan oleh karyawan dapat dihadapi dengan positif. Karena karyawan akan bertanggung jawab dalam menghadapi masalah ketika perusahaan menghargai keberanian karyawannya.

2. Variabel disiplin kerja (X2), pernyataan yang paling lemah adalah 5 yaitu "Perusahaan mengatur ketentuan pemberian imbalan diluar gaji dalam pencapaian kinerjanya" dimana hanya mencapai score sebesar 3,61 . Untuk lebih baik lagi perusahaan harus membuat sistem imbalan diluar gaji yang adil dan layak sesuai dengan hasil pencapaian kinerja karyawan. Untuk mewujudkan keadilan, program kompensasi harus dirancang dengan mempertimbangkan kontribusi karyawan maupun kebutuhan 
karyawan.

Pemberian

kompensasi dan

pengelolaannya yang baik, juga kan berdampak positif bagi produktivitas perusahaan.

3. Variabel kinerja karyawan (Y), pernyataan yang paling lemah adalah 3 yaitu "saya tidak pernah memanipulasi data untuk kepentingan pribadi” dimana hanya mencapai score sebesar 3,73. Untuk lebih baik lagi perusahaan harus memperketat pelaksanaan SOP yang sudah dibuat oleh perusahaan. SOP dibuat untuk menjamin perusahaan berjalan dengan baik dan sesuai dengan perencanaan. Jika SOP diabaikan, maka tujuan perusahaan bisa menjadi tak terkendali dan memunculkan celah untuk memanipulasi data. Dan perusahaan harus menciptakan kultur perusahaan yang baik. Pemberian visi dari atasan hingga kebawah harus berlangsung dengan benar, agar karyawan lebih mencintai nilainilai yang dituju secara bersama-sama dengan seluruh karyawan perusahaan.

4. Untuk penelitian selanjutnya sebagai bahan referensi agar dalam penelitian menggunakan variabel lain selain budaya organisasi, disiplin kerja dan kinerja karyawan.

\section{DAFTAR PUSTAKA}

A.A Anwar Prabu Mangkunegara, "Sumber Daya Manusia Perusahaan". Cetakan Ke Tigabelas. Bandung, Remaja Rosdakarya. 2015
A.A Anwar Prabu Mangkunegara, "Sumber Kerangka Berfikir Kinerja". Gramedia, Jakarta Selatan, 2014.

Algifari, "Analisis Regresi", Yogyakarta, 2014.

Anggy Henly Kumajas, Jurnal EMBA. ISSN 2303-1174, Vol.4 No.4 September 2016. Pengaruh budaya organisasi, disiplin kerja, dan lingkungan kerja secara bersama-sama dan secara parsial terhadap kinerja karyawan di PT PLN (Persero) Wilayah Suluttenggo.

Arikunto, Suharsimi, "Prosedur Penelitian Suatu Pendekatan Praktek", PT. Rineka Cipta, Jakarta, 2015.

Bachtiar Arifudin Husein, Jurnal Ilmiah Forkamma Univeritas Pamulang, ISSN (print) : 2598$9545 \&$ ISSN (online) : 2599171X. Pengaruh Disiplin Kerja Terhadap Kinerja Karyawan Pada PT.Bank Danamon Cabang Bintaro.

Ferry Ramadani Sitanggang, Jurnal Maker,ISSN: 2502-4434 Vol. 3, No. 1, (2017) 2477-Vol.2 No.3 (2017). Pengaruh Pelatihan dan Disiplin Kerja Terhadap Kinerja Pegawai pada Kantor Dinas Perindustrian dan Perdagangan, Pematangsiantar.

G.R. Terry, and Rue, Leslie W. Rue, "Dasar-dasar Manajemen", Bumi Aksara, Jakarta 2014.

Ghozali "Aplikasi Analisis Multivariate dengan Program SPSS", Edisi Kelima, Badan Penerbit Undip, Semarang, 2017.

Handoko, "Manajemen Personalia dan Sumberdaya Manusia", 
Edisi Ke enam, BPFE UGM, Yogyakarta, 2013.

Hasibuan, H. Malayu S.P. "Manajemen Sumber Daya Manusia", Edisi Revisi, Bumi Aksara. Jakarta. 2018.

Istijianto, "Aplikasi Praktis Riset

Pemasaran", Gramedia Pustaka Utama, Jakarta, 2014.

Mardi Astutik, Jurnal Bisnis, Manajemen \& Perbankan, 2016

: 121-140 ISSN 2338-4409

(Print) ISSN 2528-4649

(Online) Vol. 2 No. 2. Pengaruh

Disiplin Kerja Dan Budaya

Organisasi Terhadap Kinerja

Pegawai Sekretariat Dewan

Perwakilan Rakyat Daerah

Kabupaten Jombang.

Robbins, S.P dan Timothy A. Judge.

"Perilaku Organisasi", Edisi ke

15. Jakarta, Salemba Empat. 2013

Robbins, S.P dan Timothy A. Judge. "Perilaku Organisasi", Edisi ke 16. Jakarta, Salemba Empat. 2015

Sedarmayanti. "Manajemen Sumber Daya Manusia", PT Refika Aditama Fresco, Jakarta, 2013.

Simamora, Henry, "Manajemen Sumber Daya Manusia", Bagian Penerbit Sekolah Tinggi Ilmu Ekonomi YKPN, Yogyakarta, 2014.

Singgih Santoso "SPSS Statistik Parametik" Cetakan Kedua, PT. Elek Media, Jakarta, 2015.

Sondang P Siagian. "Manajemen Sumber Daya Manusia", Bumi Aksara, Jakarta, 2015.

Sudjana, "Metode Statistika", Edisi Keenam, Tarsito, Bandung, 2014.

Sugiyono, "Metode Penelitian Kuantitatif Kualitatif dan R \&
D", Penerbit CV. Alfabeta, Bandung, 2017.

Sugiyono. Metode Penelitian Pendidikan Pendekatan Kuantitatif, Kualitatif, dan R \& D. Alfabeta, Bandung, 2013

Sunarsi, D. (2018). Pengaruh Gaya Kepemimpinan dan Disiplin Kerja Terhadap Kinerja Karyawan Pada CV. Usaha Mandiri Jakarta. JENIUS, 1(2).

Sutrisno, Edy. "Manajemen Sumber Daya Manusia". Pranada Media Group, Jakarta. 2017

Sutrisno, Edy. "Pengaruh Disiplin kerja dan Budaya Organisasi Terhadap Kinerja Karyawan Devisi Radiologi RSUD Karidi Semarang"Vol. 12 No.2. 2014.

Veithzal Rivai. "Manajemen Sumber Daya Manusia untuk Perusahaan". Edisi ke 6, PT. Raja Grafindo Persada, Depok. 2014

Wardiah, Mia Lasmi. "Teori Perilaku dan Budaya Organisasi”, Pustaka Setia, Bandung. 2016

Wibowo. "Budaya Organisasi". Raja Grafindo Persada, Jakarta. 2016.

Yuis Ferbya Baan, Jurnal Ilmu Administrasi Bisnis, 2015: 675686 Vol.3 No.3, Pengaruh Budaya Organisasi Terhadap Kinerja Karyawan Pada Hotel Grand Victoria Di Samarinda 


\section{PANDUAN SINGKAT BAGI PENULIS JURNAL SDM JENIUS}

Panduan penulisan ini dimaksudkan untuk menyeragamkan bentuk penulisan karya ilmiah yang dikirim penulis ke redaksi Jurnal Jenius, dengan panduan penulisan sebagai berikut :

1. Naskah ditulis dalam Bahasa Indonesia dengan Abstrak Bahasa Indonesia dalam bentuk Font 12" dengan ukuran 1 Spasi dengan intisari tidak lebih dari 250 kata disertai 3 atau 4 kata kunci (keyword).

Naskah berupa Softcopy program MS Word maksimal 25 Halaman termasuk tabel dan gambar, spasi 1.

2. Sistematika penulisan disusun dengan urutan sebagai berikut :

a) Judul, nama dan alamat email penulis/peneliti tunggal.

b) Abstrak dan intisari, keyword dan kata kunci, dibuat dengan 1 kolom.

c) Batang Tubuh :

1). Pendahuluan, termasuk didalamnya intisari permasalahan

2). Perumusan Masalah

3). Tujuan Penelitian

4). Landasan teori termasuk didalamnya hipotesis dan kerangka Pemikiran

5). Metode Penelitian

6). Hasil dan Pembahasan

7). Kesimpulan

8). Daftar Pustaka

9). Seluruh isi tersebut di buat dengan 2 kolom

3. Judul ditulis dalam bentuk font Times New Roman 12" dengan huruf besar kecil dicetak tebal dan ditempatkan ditengah halaman,, serta tidak lebih dari 18 kata.

4. Tulisan karya ilmiah dalam bentuk font Times New Roman 12" dengan ukuran spasi 1,0 spasi dalam bentuk kolom.

5. Gambar diberi nomor dan keterangan, sedangkan tabel diberi nomor dan keterangan diatasnya.

6. Penulisan persamaan matematika yang terdapat pada halaman naskah hendaknya menggunakan equation editor.

7. Daftar pustaka hanya memuat literature yang dirujuk dalam keterangan dan dicantumkan pada bagian akhir naskah dilakukan dengan memberikan nomor.

8. Margin atas dan kiri $4 \mathrm{~cm}$, kanan dan bawah $3 \mathrm{~cm}$, dan ukuran kertas A4.

9. Email Redaksi : jurnalsdm.unpam@gmail.com/denoksunarsi@gmail.com 